\title{
Bifid Rib Jaw Cyst Basal Cell Nevus Syndrome: A Case Report
}

\author{
Ruchi M. Anand', Sunil S. Mishra', Shirish S. Degwekar', \\ Rahul R. Bhowate', Mukta B. Motwani², Shivlal M. Rawlani' \\ 1. Department of Oral Medicine \& Radiology, Sharad Pawar Dental College, DMIMSU, Wardha, \\ India \\ 2. Department of Oral Medicine \& Radiology, V.S.P.M. Dental College, Nagpur, India
}

\section{Corresponding Author}

\section{Dr. Ruchi M. Anand}

Department of Oral Medicine \& Radiology, Sharad Pawar Dental College, DMIMSU, Sawangi (Meghe), Wardha, Pin: 442004, Maharashtra, India

TEL : +91-9823867509 FAX :+91-9960556569 E-mail : ruchidocanand@gmail.com

Received for publication Jan 15, 2011; Returned after revision Mar 15, 2011;

Accepted for publication Apr 5, 2011

\section{- Abstract}

Gorlin-Goltz syndrome is an autosomal dominant disorder with a high degree of penetrance. It is characterized by basal cell carcinomas, odontogenic keratocysts, palmar and plantar pits and ectopic calcifications of falx cerebri. The presence of two major and one minor criteria or one major and three minor criteria are necessary to establish a diagnosis. Early diagnosis and treatment of Gorlin-Goltz syndrome, as well as family screening and genetic counseling are essential as it may be associated in $10 \%$ of patients with aggressive basal cell carcinoma and malignant neoplasias. We report here a patient with Gorlin-Goltz syndrome. 


\section{Introduction}

Several reports have appeared in the literature describing a rare syndrome variously called as Gorlin's syndrome, Gorlin-Goltz syndrome, basal cell nevus syndrome, basal cell carcinoma syndrome and nevoid basal cell carcinoma syndrome.

The nevoid basal cell carcinoma syndrome (NBCCS) was first reported by Jarish in 1894 who described a patient with multiple basal cell carcinoma, scoliosis and learning disability. Howell and Caro in 1959 were the first to associate the basal cell nevus with other cutaneous disorders and other anomalies ${ }^{1)}$. In 1960 Gorlin and Goltz defined the condition as a syndrome comprising the principal triad of multiple basal cell nevi, jaw keratocysts, and skeletal anomalies. A spectrum of other neurological, ophthalmic, endocrine, and genital manifestations are now known to be associated with this triad ${ }^{1,2)}$.

Often these patients first visit a dental hospital with the chief complaint of jaw swelling where the diagnosis of this syndrome is generally made. We would like to report one such case of Gorlin's syndrome. The purpose of this case report was to present the computed tomographic (CT) features along with three dimensional radiographic features in addition to the radiographic findings.

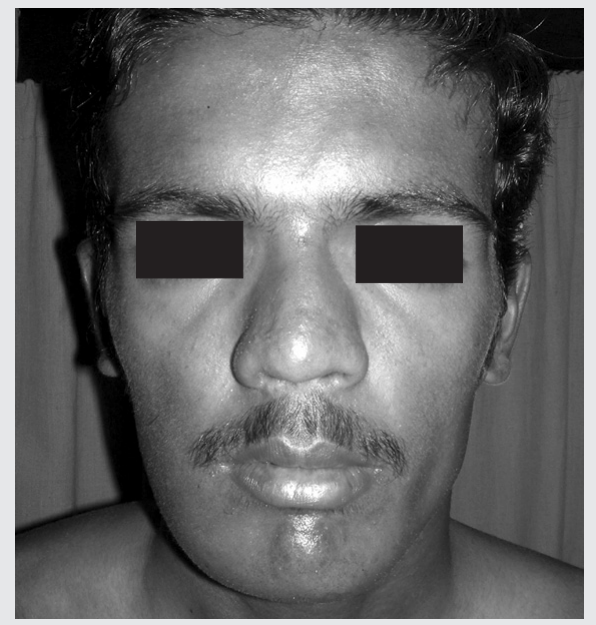

Figure 1. Extraoral examination reveals a diffuse swelling with right body of mandible.

Ruchi M. Anand, et al: Bifid Rib Jaw Cyst Basal Cell Nevus Syndrome: A Case Report. J Kor Dent Sci 2011.

\section{Case Report}

A 23-year-old male patient reported the department of oral medicine and radiology with a chief complaint of extraoral firm swelling on right side of mandible. The patient gave history of dull aching pain initially with the right mandibular molar region around 6 months back. The duration of the swelling was since last 20 days. There was no discharge of any type and he never had any abnormal sensation on the affected side. On examination, the swelling was hard and nontender. It extended from the region of first mandibular premolar to retromolar region on right side. Patient's medical, dental, family and personal history was noncontributory.

On general physical examination, the patient was moderately built and nourished, presenting with normal gait and satisfactory vital signs. On examination of face it revealed mild prognathism, frontal bossing and hypertelorism (Fig. 1). Head circumference measured was about $56 \mathrm{~cm}$ that was considered within normal limits. There was a diffuse swelling in the left middle third of the face with no secondary changes noted over it. A solitary bilateral submandibular lymph node of size $1 \times 1.5 \mathrm{~cm}$ approximately was palpable, tender, soft in consistency and mobile.

Intraoral examination revealed clinically missing permanent mandibular third molars, right side canine and second premolar. In the maxillary arch, right third molar and left canine were also missing. There was an expansile swelling in the right mandibular buccal vestibule area causing vestibular obliteration in region of first and second molars extending distally upto retromolar region. Mucosa over the swelling showed no secondary changes (Fig. 2). On palpation the swelling was tender and firm in consistency. Based on the history and clinical findings, a provisional diagnosis of
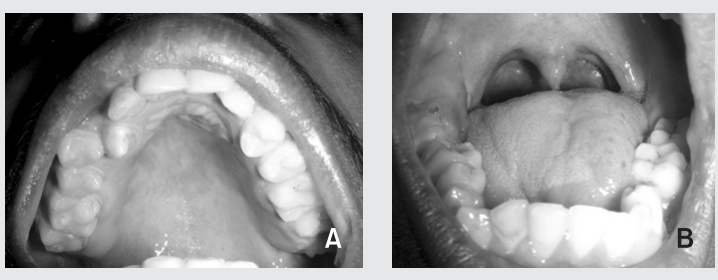

Figure 2. Intraoral examination reveals. (A) missing maxillary canine on left side, (B) diffuse swelling with the right retromolar area.

Ruchi M. Anand, et al: Bifid Rib Jaw Cyst Basal Cell Nevus Syndrome: A Case Report. J Kor Dent Sci 2011. 
dentigerous cyst in relation to clinically missing right mandibular third molar was given and a differential diagnosis of odontogenic keratocyst (OKC), ameloblastoma were considered. The patient was subjected for radiographic investigations.

Orthopantomograph revealed multiple, well defined radiolucencies with sclerotic borders in maxilla with impacted right third molar and supernumerary distomolar, left canine and in mandible with left canine and second premolar and also with right mandibular third molar as described below (Fig. 3A).

A large multilocular radiolucency was observed with right mandibular area extending anteroposteriorly from periapical region of first premolar to the mid-ramus region, and superoinferiorly from the mid-ramus area and alveolar crest in molar area to inferior border of mandible in ramus and body of mandible respectively, causing displacement of third molar. Incidentally another large unilocular well defined radiolucency was observed in the left ramus area extending superoinferiorly from the sigmoid notch to apical region of third molar and anteroposteriorly from anterior
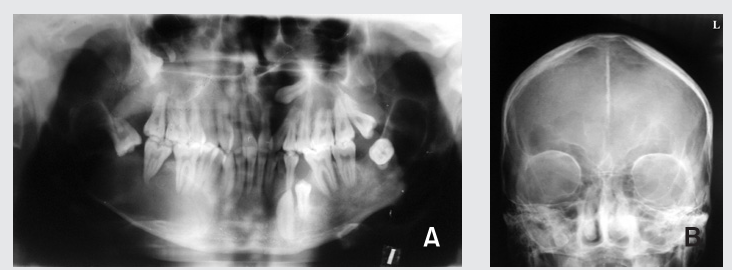

Figure 3. Radiographic investigations; (A) Panorex showing multiple cyst with upper and lower jaw, (B) PA skull showing calcification of falx cerebri.

Ruchi M. Anand, et al: Bifid Rib Jaw Cyst Basal Cell Nevus Syndrome: A Case Report. J Kor Dent Sci 2011. border of ramus to mid-ramus area was noticed. In maxillary region, well defined pericoronal radiolucency was seen with impacted left canine resulting into the divergence of roots of central and lateral left incisors. Also seen was pericoronal radiolucency in association with superiorly displaced right maxillary third molar along with small supernumerary tooth anterior to it into the right maxillary sinus.

The presence of multiple cysts in the jaws, associated with unerupted teeth, raised a suspicion of Gorlin's Syndrome and other relevant investigations were done. Anteroposterior radiographic examination of the skull showed linear calcification of the falx cerebri (Fig. 3B). Chest radiograph (Fig. 4) showed bifid ribs with $3^{\text {rd }}$ and $4^{\text {th }}$ ribs.

CT examination confirmed the orthopantomograph findings, showing multiple large expansile lesions with impacted teeth in maxilla and mandibular region, along with calcifications seen clearly in the falx cerebri. Axial view clearly showed the impacted right maxillary third molar with distomolar displaced completely in sinus region (Fig. 5). The parents and

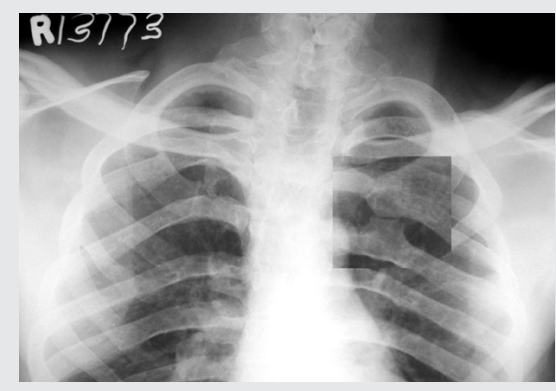

Figure 4. Chest radiograph reveals the bifid ribs with $3^{\text {rd }} \& 4^{\text {th }}$ ribs on left side (digitally enhanced).

Ruchi M. Anand, et al: Bifid Rib Jaw Cyst Basal Cell Nevus Syndrome: A Case Report J Kor Dent Sci 2011
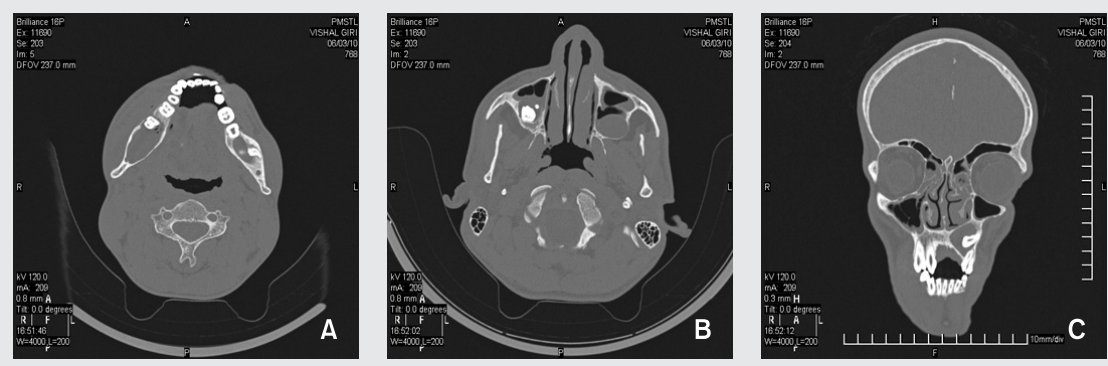

Figure 5. CT evaluation showed (A) large expansile cystic lesions with right and left mandible, (B) displaced maxillary third molar and distomolar into the right maxillary sinus, (C) a cystic lesion involving impacted left maxillary canine.

Ruchi M. Anand, et al: Bifid Rib Jaw Cyst Basal Cell Nevus Syndrome: A Case Report. J Kor Dent Sci 2011 


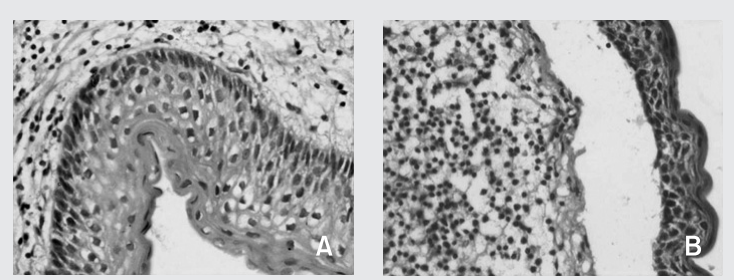

Figure 6. Micrograph at high power view ( $\mathrm{H} \& \mathrm{E}, 40 \mathrm{x})$ showing features of odontogenic keratocyst. (A) Parakeratinized stratified squamous epithelium with lack of rete ridges along with palisaded basal cell layer with hyperchromatic nuclei, (B) an artefactual separation from their basement membrane.

Ruchi M. Anand, et al: Bifid Rib Jaw Cyst Basal Cell Nevus Syndrome: A Case Report. J Kor Dent Sci 2011.

siblings of the patient were also examined clinically and radiographically; however, none of them showed any characteristics of this condition. Since the criteria of multiple cysts in the jaws (one of them being OKC), frontal bossing and falx cerebri calcification were present; a final diagnosis of Gorlin's syndrome was given. Patient was referred to the department of oral and maxillofacial surgery where enucleation of all cysts was done. And cystic lining was sent to Oral Pathology department where histopathological investigations were done. Histopathological findings (Fig. 6) confirmed the diagnosis of OKC.

\section{Discussion}

NBCCS is rare inherited disorder with multisystem manifestations, an autosomal dominant gene transmits it and whose mutation underlies NBCCS has been mapped to the long arm of chromosome $9 \mathrm{~g} 22.3 \sim \mathrm{g} 31^{2)}$. Data suggest that a product of this gene acts as tumor suppressor and NBCCS typical malformative pattern suggest that the main function is to control the growth and development of normal tissues. $^{2)}$

NBCCS prevalence has been variously estimated from 1 in 57,000 to 1 in 164,000 , but there is general agreement that the prevalence is about 1 per $60,000^{1}$. Males and females are equally affected, the clinical features of NBCCS arising in the first, second or third decade ${ }^{2}$.

The reported review revealed that, to date, there are only seven cases of the Gorlin-Goltz syndrome reported from India, out of which only two were from North India, and five were from South India. This most probably represents under-recognition due to inadequate dental facilities, espe- cially in the vast rural regions of India, outside big cities ${ }^{1,3)}$. The Gorlin-Goltz syndrome has equal predilections for either sex. Male to female ratio is 1:0.62 for OKC not associated with NBCCS and 1:1 for OKC in NBCCS, that is simple keratocysts are more common in males, but more females with NBCCS develop OKCs ${ }^{2,3)}$.

OKCs associated with NBCCS have greater predilections for the mandible than the maxilla, with $69 \%$ occurring in the mandible and $31 \%$ in the maxilla. In the mandible $43 \%$ occurs in the molar ramus region followed by $18 \%$ in the incisor-canine area, and $7 \%$ in the premolar area and in the maxilla, $14 \%$ occurs in the incisor and canine region followed by $12 \%$ in the molar tuberosities, and $3 \%$ in the premolar region ${ }^{3)}$.

In the present case two OKCs were in the molar-ramus areas of the mandible, while remaining two were in maxillary molar region and in incisor-canine region respectively. This disorder has an autosomal dominant mode of inheritance, but can arise spontaneously and have a variable phenotypic penetration $^{6}$. Almost $60 \%$ of patients with NBCCS have no known affected family members, 35 to $50 \%$ of these representing new mutations ${ }^{1,3)}$. The study done by many authors indicates that OKCs are often the first sign of NBCCS (78\%) and can be detected in patients younger than 10 years of age ${ }^{2,7}$. Multiple OKCs, arising from the rests of dental lamina of the mandible and occasionally the maxilla are common in this disorder seen almost in $75 \%$ of patients, with a peak incidence in the second and third decade of life ${ }^{1)}$. These are unilocular or multilocular, lined by stratified squamous epithelium and may contain displaced teeth. These cysts may be complicated by the development of pathological fractures, ameloblastoma and squamous cell carcinomas, and have a high rate of recurrence $^{1,8)}$.

An important clinical finding of this syndrome is the presence of multiple basal cell carcinomas, predominantly involving the face and trunk with an early age of appearance. However, about $10 \%$ of patients above the age of 30 may show no basal cell carcinomas. It has also been reported that black persons have a decreased tendency to develop basal cell carcinomas as compared to fair skinned persons; probably due to increased pigmentation of their skin. Other skin lesions include palmer or planter pits, milieu, comedones, sebaceous or epithelial cysts and dyskeratosis. In this case there were no lesions of basal cell carcinomas at any part of the body. Also seen features are rib anomalies, 
vertebral anomalies. In the skull there is early onset of calcification of the falx cerebri, tentorium cerebelli, bridging of the sella turcica due to calcification of the diaphragma sellae is seen in $60 \sim 80 \%$ of patients ${ }^{8)}$. Out of these reported findings, the finding of calcification of falx cerebri was observed in AP skull view of this case. In addition to these findings fused bifid rib was observed with third and fourth rib on left side of chest radiograph on PA view.

Bridging of the sella turcica due to calcification of the diaphragma sellae is seen in $60 \sim 80 \%$ of patients. Neurologic abnormalities include agenesis of the corpus callosum, congenital hydrocephalus, mental retardation, medulloblastomas and meningiomas. Ophthalmologic abnormalities seen are dystopia canthorum, internal strabismus, congenital blindness and hypertelorism. Abnormalities of the reproductive system are ovarian and uterine fibromas in females, and cryptorchidism and hypogonadism in males. Miscellaneous abnormalities reported are lymphatic mesenteric cysts, minor kidney abnormalities, cardiac fibromas and a tendency to develop various other neoplastic lesions such as melanomas, neurofibromas, rhabdomyosarcomas and leiomyomas $^{1,6,8,9)}$.

A diagnostic criteria for NBSCCS, which was modified in 1997 which included multiple basal cell carcinoma or one occurring under age of 20 years, histologically proven OKCs of the jaws, palmar or plantar pits OKCs of the jaws, bifid, fused or markedly splayed ribs, first degree relative with NBCCS as major criteria and macrocephaly, congenital malformations (cleft lip or palate, frontal bossing, coarse face, moderate or severe hypertelorism), other skeletal abnor-

\section{References}

1. Manfredi M, Vescovi P, Bonanini M, Porter S. Nevoid basal cell carcinoma syndrome: a review of the literature. Int J Oral Maxillofac Surg. 2004; 33: 117-24.

2. Karthiga KS, Sivapatha Sundharam B, Manikandan R. Nevoid basal cell carcinoma syndrome. Indian J Dent Res. 2006; 17: 50-3.

3. Jawa DS, Sircar K, Somani R, Grover N, Jaidka S, Singh S. GorlinGoltz syndrome. J Oral Maxillofac Pathol. 2009; 13: 89-92.

4. Bitar GJ, Herman CK, Dahman MI, Hoard MA. Basal cell nevus syndrome: guidelines for early detection. Am Fam Physician. 2002; 65: 2501-4.

5. Lo Muzio L. Nevoid basal cell carcinoma syndrome (Gorlin syndrome). Orphanet J Rare Dis. 2008; 3: 32.

6. Patil K, Mahima VG, Gupta B. Gorlin syndrome: a case report. J Indian malities (sprengel's deformity, marked pectus deformity, marked syndactyly of the digits), radiological abnormalities (bridging of sella turcica, vertebral anomalies such as hemivertebrae, fusion or elongation of vertebral bodies, defects of hands and feet), ovarian fibromas and medulloblastoma as minor criterias $^{5}$. According to him, diagnosis of Gorlin's syndrome can be established when two major or one major and two minor criteria as described below are present. There should be at least two or one major criteria or one major and two minor criteria for the diagnosis of $\mathrm{NBCCS}^{2,3,6)}$. Leonardi et al. in 2010 suggested the inclusion of atlanto-occipital ligament calcification as diagnostic feature for NBCCS in addition to other criterias ${ }^{10)}$.

The present case was diagnosed as Gorlin-Goltz syndrome and was established by the presence of three major criteria (viz, multiple OKCs, bifid and calcified falx cerebri) and two minor criteria (viz, frontal bossing and hypertelorism). This syndrome has a number of skeletal and systemic radiological manifestations, but the most common findings are multiple OKCs and basal cell nevus which should alert the radiologist and can aid in the diagnosis of this syndrome. Early diagnosis and treatment is important to prevent long term squeal including malignancy and oro-maxillofacial deformation and destruction.

In conclusion, as $\mathrm{OKC}$ is frequently the presenting manifestation of this syndrome, this condition requires early diagnosis to prevent clinical progression and complications along with oro-maxillofacial deformation.

Soc Pedod Prev Dent. 2005; 23: 198-203.

7. In: Neville BW, Damm DD, Allen CM, Bouquot JE: Oral and Maxillofacial Pathology. 2nd ed. Philadelphia: Saunders; 2002. p. 598601.

8. Gandage SG, Rahalkar M, Domkundwar S. Gorlin's syndrome radiographic and CT manifestations. Indian J Radiol Imaging. 2003; 13: $19-22$.

9. Rai S, Gauba K. Jaw cyst-basal cell nevus-Bifid rib syndrome: a case report. J Indian Soc Pedod Prev Dent. 2007; 25: 137-9.

10. Leonardi R, Santarelli A, Barbato E, Ciavarella D, Bolouri S, Härle F, Palazzo G, Lo Muzio L. Atlanto-occipital ligament calcification: a novel sign in nevoid basal cell carcinoma syndrome. Anticancer Res. 2010; 30: 4265-7. 